OPEN ACCESS

Edited by:

Peter Sporns,

University Hospital of

Basel, Switzerland

Reviewed by:

Christian Weimar,

Essen University Hospital, Germany Adria Arboix

Sacred Heart University

Hospital, Spain

*Correspondence:

James R. Brorson

jbrorson@uchicago.edu

Specialty section:

This article was submitted to

Stroke,

a section of the journal

Frontiers in Neurology

Received: 27 April 2021

Accepted: 28 July 2021

Published: 10 September 2021

Citation:

Bulwa ZB, Mendelson SJ and Brorson JR (2021) Acute Secondary

Prevention of Ischemic Stroke:

Overlooked No Longer

Front. Neurol. 12:701168.

doi: 10.3389/fneur.2021.701168

\section{Acute Secondary Prevention of Ischemic Stroke: Overlooked No Longer}

\author{
Zachary B. Bulwa ${ }^{1}$, Scott J. Mendelson ${ }^{2}$ and James R. Brorson ${ }^{2 *}$ \\ ${ }^{1}$ Department of Neurology, Rush University Medical Center, Chicago, IL, United States, ${ }^{2}$ Department of Neurology, The \\ University of Chicago, Chicago, IL, United States
}

Recent studies of interventions initiated acutely following onset of minor ischemic stroke or transient ischemic attack (TIA) have disclosed early stroke recurrence rates that are substantially higher than long-term recurrence rates and that can be reduced by acute antiplatelet treatment interventions. These observations, bolstered by analysis based on kinetic modeling of the time course of recurrence following initial events, suggest that acute stroke patients experience an underlying vulnerable state that quickly transitions to a more stable state. Some evidence also supports the benefits of early treatment with direct-acting oral anticoagulants in cardioembolic stroke and of continuation or early initiation of statin therapy in atherosclerotic stroke. Treatment of ischemic stroke should address the transient vulnerable state that follows the initial event, employing measures aiming to avert early recurrence of thromboembolism and to promote stabilization of vulnerable arterial plaque. These measures constitute acute secondary prevention following ischemic stroke.

Keywords: acute stroke, ischemic stroke, antiplatelet, statin therapy, timing of intervention, anticoagulation timing

\section{INTRODUCTION}

In the hospital care of acute ischemic stroke patients, initial clinical management is tightly focused on interventions aimed to reverse ischemia through induced reperfusion and to limit early complications of brain infarction. Investigations are undertaken to rapidly explore potential mechanisms of stroke, and planning for discharge quickly begins, with selection of the appropriate rehabilitation program to meet the patient's needs. Careful consideration of preventing a subsequent stroke is often relegated to the ambulatory setting. Instead, secondary prevention needs to be considered acutely, as the highest risk for recurrent stroke is typically in the first several days following an initial ischemic event $(1,2)$. Risks of early recurrence depend on the subtype of ischemic stroke and on individual patient features, and acute interventions to prevent recurrence need to be targeted to the specifics of each case.

\section{ANTIPLATELET TREATMENT IN MINOR STROKE OR TRANSIENT ISCHEMIC ATTACK}

Early secondary stroke prevention trials generally had enrollment windows extended for months following the ictus, missing early detection of stroke recurrence. Exceptions were the Chinese Acute Stroke Trial (3) and the International Stroke Trial (4), which examined early initiation 
of aspirin within $48 \mathrm{~h}$ following ischemic stroke, demonstrating modestly high early recurrence rates that were reduced by aspirin. More recently, trials of acute treatment of minor ischemic stroke or TIA with augmented antiplatelet regimens, such as CHANCE (Clopidogrel in High-Risk Patients with Acute Non-disabling Cerebrovascular Events) (5), SOCRATES (Acute Stroke Or Transient IsChaemic Attack TReated With Aspirin or Ticagrelor and Patient OutcomES) (6), POINT (Platelet-Oriented Inhibition in New TIA and Minor Ischemic Stroke) (7), and THALES (Transient IscHaemic Attack Treated With TicAgreLor and ASA for PrEvention of Stroke and Death) (8), with randomization and tracking of subjects occurring within $12-24 \mathrm{~h}$ of stroke onset, have demonstrated a clear and consistent finding: the stroke recurrence rate is highest within the first few days following stroke, slowing to a second phase of lower recurrence rate, sustained over subsequent months. In each of these trials of acute antiplatelet regimens, the majority of outcome events, predominantly consisting of ischemic strokes, occurred within the first 7 days, in both control and active treatment groups (see Table 1). Further, the effects of dual antiplatelet therapy with aspirin and clopidogrel (in CHANCE and POINT) or with ticagrelor (in THALES) over aspirin monotherapy appeared to be confined to a reduction of the rate of early recurrence, with plots of subsequent survival free of stroke after the first few weeks running in parallel in dual antiplatelet therapy and aspirin monotherapy groups.

Analyses of the CHANCE and POINT trials have confirmed that the benefits of dual antiplatelet therapy over aspirin alone accrued entirely in the first few weeks following stroke, while the small excess bleeding risk accompanying dual antiplatelet therapy continued at an approximately constant rate over the entire duration of the study period $(9,10)$. For these reasons, several authors have recommended adoption of a dual antiplatelet therapy regimen modified from that of the POINT trial, extending for only a 3-week period rather than 3 months, to gain the early benefit without the extended increased hemorrhage risk.

The aforementioned antiplatelet trials were selected for patients with minor stroke or TIA, arguably enriching strokes of atherosclerotic origin by excluding strokes due to cardioembolism. A post-hoc analysis of the CHANCE trial data found that the risk of recurrent stroke was substantially greater in those patients with intracranial atherosclerosis as the probable mechanism of stroke and that risk reductions of dual antiplatelet therapy were numerically confined to this group, though the interaction of subgroup with treatment effect did not reach significance (11). Furthermore, pre-specified analyses of the SOCRATES and THALES trials showed a superiority of ticagrelor (alone or added) over aspirin alone for prevention of stroke recurrence that was confined to the subgroup of subjects with identified ipsilateral atherosclerotic disease $(12,13)$. A plausible interpretation is that embolic events due to unstable or ulcerated atherosclerotic arterial plaques are particularly associated with high rates of recurrent embolism for a brief period, perhaps until ulceration heals or intraplaque inflammation quiets, explaining both the transient high rate of early stroke recurrence and the efficacy of augmented antiplatelet therapy.

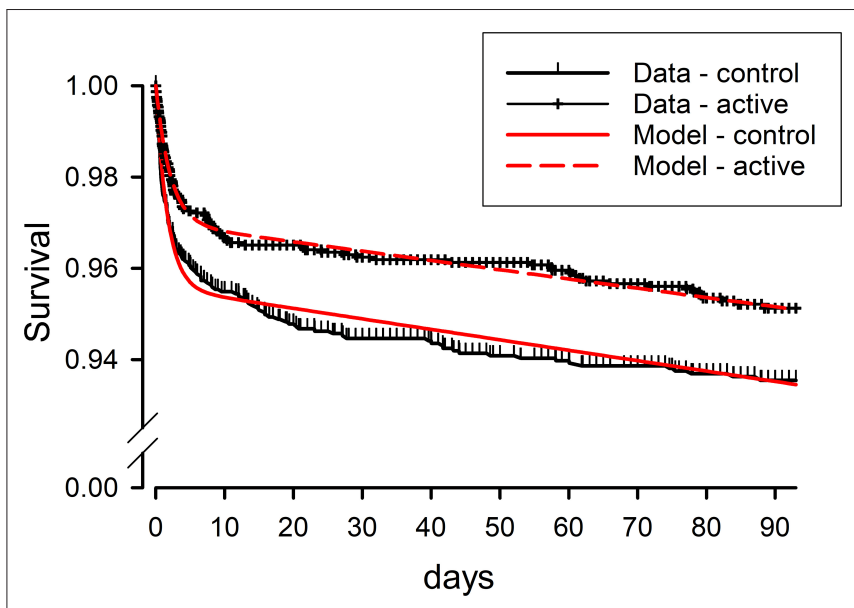

FIGURE 1 | Clinical survivor function data from the POINT trial for active treatment (clopidogrel + aspirin) and control (aspirin) as-treated groups, compared to results predicted by fitting of these data by a mathematical model based on kinetic analysis. Survival free from the composite primary endpoint of ischemic stroke, myocardial infarction, or death is plotted vs. time from study entry, within $12 \mathrm{~h}$ of the initial minor stroke or TIA. The kinetic model postulates two clinical states for patients following initial stroke or TIA, one state vulnerable to a high rate of recurrence of ischemic events, but short-lived, and the other state stabilized, with ischemic events recurring at a low rate. Modified from Brorson and Bulwa (14).

While the front-loading of stroke recurrence demonstrated in these trials has been repeatedly recognized, there has been less explicit recognition of a clear implication: that subjects in the acute stroke prevention trials must be distributed between more than one clinical state to produce this sort of temporal pattern. If all subjects were in a single state with constant risks of stroke recurrence, the kinetics of survival free of stroke recurrence would follow a simple exponential decline. Instead, the two phases of recurrence rates seen in trial outcome data require a two-state kinetic model, postulating a transient vulnerable state and a long-term stabilized state. Such a model produces a close mathematical match to the temporal kinetics of Kaplan-Meier curves from the POINT trial (Figure 1). It also gives estimates for the kinetic rates of event recurrence in the vulnerable and stabilized states and for the rate of transition from the vulnerable to stabilized state (14). Notably, the predicted kinetic rates for stroke recurrence in the vulnerable state are $\sim 100$-fold greater than the rates in the stabilized state, underscoring the imperative to direct acute preventative treatment to the mechanisms producing the vulnerable state.

\section{ANTICOAGULATION IN CARDIOEMBOLIC STROKE}

The following question then arises: whether in cardioembolic stroke there is a similar two-phase time course of stroke recurrence, with a high early rate followed by a constant lower rate over subsequent months and years. Older trials 


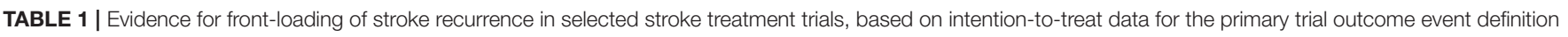
(Ml: myocardial infarction).

\begin{tabular}{|c|c|c|c|c|c|c|c|}
\hline \multirow[t]{2}{*}{ Trial } & \multirow[t]{2}{*}{$N$} & \multirow[t]{2}{*}{ Treatments (following load) } & \multicolumn{3}{|c|}{ Event rates } & \multirow[t]{2}{*}{ Fraction in 7 days } & \multirow{2}{*}{$\begin{array}{l}\text { Hemorrhage } \\
\text { rates } \\
90 \text { days }\end{array}$} \\
\hline & & & 7 days & 30 days & 90 days & & \\
\hline \multirow{2}{*}{$\begin{array}{l}\text { CHANCE } \\
\text { Primary outcome: any } \\
\text { stroke }\end{array}$} & 2,586 & Aspirin 75 mg QD & $8.7 \%$ & $10.2 \%$ & $11.7 \%$ & 0.74 & $0.3 \%$ \\
\hline & 2,584 & Clopidogrel $75 \mathrm{mg}$ plus aspirin $75 \mathrm{mg}$ QD $\times 21$ days & $5.9 \%$ & $7.3 \%$ & $8.2 \%$ & 0.72 & $0.3 \%$ \\
\hline \multirow{2}{*}{$\begin{array}{l}\text { SOCRATES } \\
\text { Primary outcome: } \\
\text { stroke, MI, or death }\end{array}$} & 6,610 & Aspirin 100 QD & $4.9 \%$ & $5.8 \%$ & $7.5 \%$ & 0.65 & $0.6 \%$ \\
\hline & 6,589 & Ticagrelor 90 BID & $3.9 \%$ & $5.2 \%$ & $6.7 \%$ & 0.58 & $0.5 \%$ \\
\hline \multirow{2}{*}{$\begin{array}{l}\text { POINT } \\
\text { Primary outcome: } \\
\text { stroke, MI, or vascular } \\
\text { death }\end{array}$} & 2,449 & Aspirin 50-325 mg QD & $4.6 \%$ & $5.9 \%$ & $6.5 \%$ & 0.71 & $0.4 \%$ \\
\hline & 2,432 & Clopidogrel 75 mg QD plus aspirin & $2.9 \%$ & $4.1 \%$ & $5.0 \%$ & 0.58 & $0.9 \%$ \\
\hline \multirow{2}{*}{$\begin{array}{l}\text { THALES } \\
\text { Primary outcome: } \\
\text { stroke or death }\end{array}$} & 5,493 & Aspirin 75-100 mg QD & $5.3 \%$ & $6.6 \%$ & $(-)$ & 0.80 & $\begin{array}{l}(0.1 \% \text { at } 30 \\
\text { days) }\end{array}$ \\
\hline & 5,523 & Ticagrelor 90 mg BID plus aspirin & $4.2 \%$ & $5.5 \%$ & $(-)$ & 0.76 & $\begin{array}{l}(0.5 \% \text { at } 30 \\
\text { days })\end{array}$ \\
\hline \multirow{2}{*}{$\begin{array}{l}\text { Yaghi et al. (23) (stroke } \\
\text { in atrial fibrillation; } \\
\text { observational) Primary } \\
\text { outcome: stroke, TIA, } \\
\text { or arterial embolism }\end{array}$} & 862 & DOACs & $1.7 \%$ & $3.1 \%$ & $4.2 \%$ & 0.40 & \\
\hline & 389 & Warfarin & $3.3 \%$ & $5.3 \%$ & $8.0 \%$ & 0.41 & \\
\hline
\end{tabular}

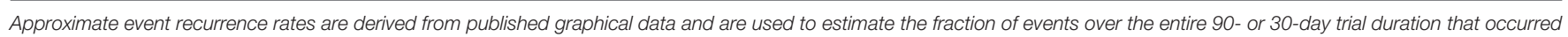
within the first 7 days. In each of these studies, ischemic stroke constituted the majority of outcome events.

of anticoagulation for atrial fibrillation or cardiomyopathy did not selectively enroll patients in the immediate period following stroke, missing any opportunity to detect an early high-risk phase of stroke recurrence (15-17). A large singlecenter case series showed a substantial rate of $3.9 \%$ of recurrent embolism within 7 days in cardioembolic stroke patients strongly predicting in-hospital mortality (18). Thus, while data are limited regarding early recurrence rates following cardioembolic strokes, there may be reason for urgency in starting anticoagulation therapy for secondary prevention. Current guidelines only recommend that in the setting of atrial fibrillation, it is reasonable to start anticoagulation within 4-14 days of the onset of symptoms (19), but it is also reasonable to delay anticoagulation past 14 days in patients with higher risks (20).

The optimal timing of anticoagulation with direct-acting oral anticoagulants (DOACs) following ischemic stroke in atrial fibrillation is the focus of ongoing trials. Existing evidence shows that anticoagulation with DOACs in the early period (3-5 days) following ischemic stroke at least can be applied with a low frequency of associated symptomatic intracranial hemorrhage events $(21,22)$. Analysis of multicenter observational data comparing different strategies for anticoagulation following atrial fibrillation-associated stroke supports the use of DOACs over warfarin and supports direct initiation of oral treatment rather than bridging with heparin or heparinoids (23). These data show a noticeable front-loading of recurrent ischemic stroke, especially in the warfarin-treated patients, with events occurring in $\sim 3 \%$ of subjects in the first 7 days after stroke, compared to $8 \%$ at 90 days (see Table 1). Bleeding events occurred predominantly with bridging with heparin or heparinoids in the first weeks following stroke, with a $3.1 \%$ bleeding risk within 30 days. Thus, the currently available data suggest an elevation of early embolism recurrence after atrial fibrillation-associated ischemic stroke, which may be safely countered by early initiation of direct oral anticoagulants, without heparin bridging. Further studies are in progress aiming to better define the optimal timing of initiation of anticoagulation (21).

\section{CERVICAL CAROTID ARTERY DISEASE MANAGEMENT}

Cervical carotid artery disease raises an additional dilemma regarding acute secondary prevention: unstable plaque in the internal carotid artery is well-recognized to lead to a very high risk for recurrent stroke, particularly in the early period following initial stroke or TIA (24), and yet risks of hemorrhagic transformation of recent infarction raise concerns 
regarding early carotid revascularization with endarterectomy or stenting procedures. At one time, surgeons approached acutely symptomatic carotid stenoses with caution, frequently delaying surgery for 3 weeks or more, theoretically allowing restoration of cerebrovascular reactivity in the recently ischemic tissue before revascularizing the symptomatic carotid. However, secondary analysis of the European Carotid Surgery Trial and North American Symptomatic Carotid Endarterectomy Trial data for effects of timing of surgery following symptoms showed that in patients with symptomatic stenosis, risk reductions provided by surgery fell substantially when surgery was delayed beyond 2 weeks (24). Risks of surgery are no higher in neurologically stable patients with recent TIA or nondisabling stroke when operated on early, within the first 1 week from the event, as compared to those undergoing endarterectomy later (25). American Heart Association guidelines recommend that it is reasonable to perform carotid revascularization, when indicated, within 2 weeks of a TIA or minor nondisabling stroke (20).

A subgroup of cervical carotid stroke patients has a distinctive pattern of crescendo TIA or stroke-in-evolution, often due to hypoperfusion resulting from severe carotid stenosis, with progressive symptoms unresponsive to medical stabilization, and a high risk of severe stroke outcome. These observations have driven a trend toward earlier carotid revascularization in selected cases of unstable ischemia, with acceptable complication risks reported in a large observational study of carotid endarterectomy performed within $48 \mathrm{~h}$ of onset of TIA or strokein-evolution (26). However, a systemic review of published studies indicates that early intervention in such cases clearly comes at the cost of higher absolute risks of stroke and death (25). Risks and potential benefits of carotid intervention depend on the particular clinical context, including clinical or radiographic evidence for unstable plaque or hypoperfusion due to occlusion, and therefore, decisions regarding the performance and timing of revascularization need to be individualized for each patient.

\section{CRYPTOGENIC STROKE}

One-quarter to one-third of ischemic strokes remain unexplained after standard inpatient etiologic evaluations. Many of these cases have features strongly pointing to an embolic mechanism of stroke. These cases have been categorized as "Embolic stroke of undetermined source," or ESUS, and the supposition that many of these events are occurring due to cardioembolism has led to testing of anticoagulation as a potentially more efficacious method of secondary prevention than aspirin. Thus far, randomized trials have not shown any superiority of DOACs over aspirin for secondary prevention following ESUS (27, 28). These trials had long windows of enrollment following the initial stroke of up to 6 months, and thus, they do not provide insight into the rate of early recurrence of stroke. Further study is needed to determine if active short-lived mechanisms producing the initial stroke in ESUS may also contribute to increased rates of early stroke recurrence in this setting.

\section{EFFECTS OF LIPID-LOWERING THERAPY}

Though the role of statins in long-term secondary prevention in stroke of presumed atherosclerotic mechanism is wellestablished, data regarding early initiation of statin therapy are limited. A large retrospective study showed that patients on statins prior to stroke hospitalization had improved poststroke survival, especially when statins were restarted with 2 days of the stroke, whereas statin withdrawal at the time of the stroke was associated with increased mortality (29). A small randomized trial comparing a 3-day interruption in statin treatment to statin continuation at the time of stroke showed higher rates of early neurological deterioration and of dependency at 3 months with statin withdrawal (30). Two small randomized trials have attempted to test the effect of early vs. late initiation of statin therapy after stroke. Starting atorvastatin $80 \mathrm{mg}$ at day 3 vs. at day 30 made no significant difference in the growth of infarction volume (31). Various statins started within $24 \mathrm{~h}$ vs. after 7 days following stroke in the ASSORT (Administration of Statin on Acute Ischemic Stroke Patient) trial did not significantly affect disability at 90 days or the rate of ischemic stroke recurrence (32). Thus, prospective trials have not yet defined the best timing for initiation of statins following stroke. Despite the lack of definitive evidence, existing data suggest that statin therapy should not be withdrawn at the time of stroke. Instead, in patients previously on treatment, statins should be continued at the time of stroke, and in patients with appropriate indications not previously treated with statins, they should be initiated within 1 or 2 days of the stroke.

\section{DISCUSSION}

Driven by recent clinical trials examining the early hours following the initial stroke, management of acute stroke and TIA has begun to address acute secondary prevention. Clear evidence has established the efficacy of dual antiplatelet therapy with clopidogrel and aspirin and has suggested a possible role for ticagrelor. In atrial fibrillation-related stroke, early institution of anticoagulant therapy with DOACs may also safely prevent an initial wave of stroke recurrence. Statin treatment during and after stroke admission is associated with lowered mortality and dependency following the stroke and is generally indicated for long-term secondary prevention. Further investigations will need to explore ways to promote plaque stabilization following initial atheroembolic events from ruptured plaque, perhaps the chief entity accounting for the vulnerable state transiently following an initial ischemic event. Efforts aimed at preventing early stroke recurrence have long-term consequences for patients, including averting cognitive impairment, a frequent consequence of incident and recurrent lacunar stroke $(33,34)$. Hospital care 
for acute stroke patients must begin to emphasize evidencebased acute secondary prevention in the transition between acute treatments and long-term preventative care.

\section{AUTHOR CONTRIBUTIONS}

$\mathrm{ZB}$ and JB developed the concept for this article. JB wrote the first draft and edited further drafts. ZB and SM reviewed and revised

\section{REFERENCES}

1. Johnston SC, Gress DR, Browner WS, Sidney S. Short-term prognosis after emergency department diagnosis of TIA. JAMA. (2000) 284:29016. doi: 10.1001/jama.284.22.2901

2. Amarenco P, Lavallée PC, Labreuche J, Albers GW, Bornstein NM, Canhão P, et al. One-year risk of stroke after transient ischemic attack or minor stroke. N Engl J Med. (2016) 374:1533-42. doi: 10.1056/NEJMoa1412981

3. CAST (Chinese Acute Stroke Trial) Collaborative Group. CAST: randomized placebo-controlled trial of early aspirin use in 20,000 patients with acute ischaemic stroke. Lancet. (1997) 349:1641-9.

4. International Stroke Trial Collaborative Group. The International Stroke Trial (IST): a randomised trial of aspirin, subcutaneous heparin, both, or neither among 19435 patients with acute ischaemic stroke. International Stroke Trial Collaborative Group. Lancet. (1997) 349:1569-81.

5. Wang Y, Wang Y, Zhao X, Liu L, Wang D, Wang C, et al. Clopidogrel with aspirin in acute minor stroke or transient ischemic attack. $N$ Engl J Med. (2013) 369:11-9. doi: 10.1056/NEJMoa1215340

6. Johnston SC, Amarenco P, Albers GW, Denison H, Easton JD, Evans SR, et al. Ticagrelor versus aspirin in acute ischemic stroke or transient ischemic attack. N Engl J Med. (2016) 375:35-43. doi: 10.1056/NEJMoa1603060

7. Johnston SC, Easton JD, Farrant M, Barsan W, Conwit RA, Elm JJ, et al. Clopidogrel and aspirin in acute ischemic stroke and high-risk TIA. N Engl J Med. (2018) 379:215-25. doi: 10.1056/NEJMoa1800410

8. Johnston SC, Amarenco P, Denison H, Evans SR, Himmelmann A, James S, et al. Ticagrelor and aspirin or aspirin alone in acute ischemic stroke or TIA. $N$ Engl J Med. (2020) 383:207-17. doi: 10.1056/NEJMoa1916870

9. Pan Y, Jing J, Chen W, Meng X, Li H, Zhao X, et al. Risks and benefits of clopidogrel-aspirin in minor stroke or TIA. Time course analysis of CHANCE. Neurology. (2017) 88:1906-11. doi: 10.1212/WNL.0000000000003941

10. Johnston SC, Elm JJ, Easton JD, Farrant M, Barsan WG, Kim AS, et al. Time course for benefit and risk of clopidogrel and aspirin after acute transient ischemic attack and minor ischemic stroke. A secondary analysis from the POINT randomized trial. Circulation. (2019) 40:65864. doi: 10.1161/CIRCULATIONAHA.119.040713

11. Liu L, Wong KSL, Leng X, Pu Y, Wang Y, Jing J, et al. Dual antiplatelet therapy in stroke and ICAS. Subgroup analysis of CHANCE. Neurology. (2015) 85:1154-62. doi: 10.1212/WNL.0000000000001972

12. Amarenco P, Albers GW, Denison H, Easton JD, Evans SR, Held P, et al. Efficacy and safety of ticagrelor versus aspirin in acute stroke or transient ischaemic attack of atherosclerotic origin: a subgroup analysis of SOCRATES, a randomized, double-blind, controlled trial. Lancet Neurol. (2017) 26:30110. doi: 10.1161/STROKEAHA.117.017217

13. Amarenco P, Denison H, Evans SR, Himmelmann A, James S, Knutsson $\mathrm{M}$, et al. Ticagrelor added to aspirin in acute nonsevere ischemic stroke or transient ischemic attack of atherosclerotic origin. Stroke. (2020) 51:350413. doi: 10.1161/STROKEAHA.120.032239

14. Brorson JR, Bulwa ZB. Two-state kinetic model of rates of stroke recurrence in the POINT study population. Stroke. (2021) 52:14469. doi: 10.1161/STROKEAHA.120.031447

15. Patel MR, Mahaffey KW, Garg J, Pan G, Singer DE, Hacke W, et al. Rivaroxaban versus warfarin in nonvalvular atrial fibrillation. $N$ Engl J Med. (2011) 365:883-91. doi: 10.1056/NEJMoa1009638

16. Easton JD, Lopes RD, Bahit MC, Wojdyla DM, Granger CB, Wallentin $\mathrm{L}$, et al. Apixaban compared with warfarin in patients with atrial the article. All authors agree to be accountable for the content of the work.

\section{FUNDING}

This work was internally funded through academic support of the Department of Neurology of the University of Chicago. fibrillation and previous stroke or transient ischemic attack: a subgroup analysis of the ARISTOTLE trial. Lancet Neurol. (2012) 1:503-11. doi: 10.1016/S1474-4422(12)70092-3

17. Homma S, Thompson JL, Pullicino PM, Levin B, Freudenberger RS, Teerlink $\mathrm{JR}$, et al. Warfarin and aspirin in patients with heart failure and sinus rhythm. N Engl J Med. (2012) 366:1859-69. doi: 10.1056/NEJMoa1202299

18. Arboix A, Garcia-Eroles L, Massons J, Oliveres M. redictive clinical factors of in-hospital mortality in 231 consecutive patients with cardioembolic cerebral infarction. Cerebrovasc Dis. (1998) 8:8-13. doi: 10.1159/000015809

19. Powers WJ, Rabinstein AA, Ackerson T, Adeoye OM, Bambakidis NC, Becker $\mathrm{K}$, et al. Guidelines for the early management of patients with acute ischemic stroke: 2019 update to the 2018 guidelines for the early management of acute ischemic stroke: a guideline for healthcare professionals from the American Heart Association/American Stroke Association. Stroke. (2019) 50:e344-e418. doi: 10.1161/STR.0000000000000211

20. Kernan WN, Ovbiagele B, Black HR, Bravata DM, Chimowitz MI, Ezekowitz $\mathrm{MD}$, et al. Guidelines for the Prevention of Stroke in Patients with stroke and transient ischemic attack: a Guideline for Healthcare professionals from the American Heart Association/American Stroke Association. Stroke. (2014) 45:2160-236. doi: 10.1161/STR.0000000000000024

21. Seiffge DJ, Werring D, Paciaroni M, Dawson J, Warach S, Milling TJ, et al Timing of anticoagulation after recent ischemic stroke in patients with atrial fibrillation. Lancet Neurol. 18:117-26. doi: 10.1016/S1474-4422(18)30356-9

22. Labovitz AJ, Rose DZ, Fradley MG, Meriwether JN, Renati S, Martin R, et al. Early apixaban use following stroke in patients with atrial fibrillation. Results of the AREST trial. Stroke. (2021) 52:1164-71. doi: 10.1161/STROKEAHA.120.030042

23. Yaghi S, Mistry E, Liberman AL, Giles J, Asad SD, Liu A, et al. Anticoagulation type and early recurrence in cardioembolic stroke. The IAC study. Stroke. (2020) 51:2724-32. doi: 10.1161/STROKEAHA.120.028867

24. Rothwell PM, Eliasziw M, Gutnikov SA, Warlow CP, Barnett HJ, Carotid Endarterectomy Trialists Collaboration. Endarterectomy for symptomatic carotid stenosis in relation to clinical subgroups and timing of surgery. Lancet. (2004) 63:915-24. doi: 10.1016/S0140-6736(04)15785-1

25. Rerkasem K, Rothwell P. Systematic review of the operative risks of carotid endarterectomy for recently symptomatic stenosis in relation to the timing of surgery. Stroke. (2009) 40:e564-e72. doi: 10.1161/STROKEAHA.109.558528

26. Ferrero E, Ferri M, Viazzo A, Labate C, Berardi G, Pecchio A, et al. A retrospective study on early carotid endarterectomy within 48 hours after transient ischemic attack and stroke in evolution. Ann Vasc Surg. (2014) 28:227-38. doi: 10.1016/j.avsg.201 3.02.015

27. Hart RG, Sharma M, Nundl H, Kasner SD, Bangdiwala SI, Berkowitz SD, et al. Rivaroxaban for stroke prevention after embolic stroke of undetermined source. N Engl J Med. (2018) 378:2191-201. doi: 10.1056/NEJMoa18 02686

28. Diener H-C, Sacco RL, Easton JD, Granger CB, Bernstein RA, Uchiyama S, et al. Dabigatran for prevention of stroke after embolic stroke of undetermined source. N Engl J Med. (2019) 380:1906-17. doi: 10.1056/NEJMoa1813959

29. Flint AC, Kamel H, Navi BB, Rao VA, Faigeles BS, Conell C, et al. Statin use during ischemic stroke hospitalization is strongly associated with improved poststroke survival. Stroke. (2012) 43:147-54. doi: 10.1161/STROKEAHA.111.627729

30. Blanco $M$, Nombela $F$, Catellanos $M$, Rodriguez-Yáñez $M$, García-Gil M, Leira $\mathrm{R}$, et al. Statin treatment withdrawal in 
ischemic stroke. A controlled randomized study. Neurology. (2007) 69:904-10. doi: 10.1212/01.wnl.0000269789.09277.47

31. Beer C, Blacker D, Bynevelt M, Hankey GJ, Puddey IB. A randomized placebo controlled trial of early treatment of acute ischemic stroke with atorvastatin and irbesartan. Int J Stroke. (2012) 7:104-11. doi: 10.1111/j.1747-4949.2011.00653.x

32. Yoshimura S, Uchida K, Daimon T, Takashima R, Kimura K, Morimoto $\mathrm{T}$, et al. Randomized controlled trial of early versus delayed statin therapy in patients with acute ischemic stroke. ASSORT Trial (Administration of statin on acute ischemic stroke patient). Stroke. (2017) 48:305763. doi: 10.1161/STROKEAHA.117.017623

33. Jacova C, Pearce LA, Costello R, McClure LA, Holliday SL, Hart RG, et al. Cognitive impairment in lacunar strokes: the SPS3 trial. Ann Neurol. (2012) 72:351-62. doi: 10.1002/ana.23733

34. Blanco-Rojas L, Arboix A, Canovas D, Grau-Olivares M, Morera JCO, Parra O. Cognitive profile in patients with a first-ever lacunar infarct with and without silent lacunes: a comparative study. BMC Neurol. (2013) 13:203. doi: 10.1186/1471-2377-13-203
Conflict of Interest: The authors declare that the research was conducted in the absence of any commercial or financial relationships that could be construed as a potential conflict of interest.

Publisher's Note: All claims expressed in this article are solely those of the authors and do not necessarily represent those of their affiliated organizations, or those of the publisher, the editors and the reviewers. Any product that may be evaluated in this article, or claim that may be made by its manufacturer, is not guaranteed or endorsed by the publisher.

Copyright (C) 2021 Bulwa, Mendelson and Brorson. This is an open-access article distributed under the terms of the Creative Commons Attribution License (CC BY). The use, distribution or reproduction in other forums is permitted, provided the original author(s) and the copyright owner(s) are credited and that the original publication in this journal is cited, in accordance with accepted academic practice. No use, distribution or reproduction is permitted which does not comply with these terms. 